\title{
PRÊMIOS DE RECONHECIMENTO COMO INSTRUMENTO DE PROMOÇÃO À INOVAÇÃO NAS EMPRESAS BRASILEIRAS
}

\section{SANDRO CELSO DE SOUZA}

Mestrando em Políticas Públicas Estratégias e Desenvolvimento Instituto de Economia da Universidade Federal do Rio de Janeiro (UFRJ) E-mail: sandroc_souza@hotmail.com

CAETANO CHRISTOPHE ROSADO PENNA Doutor em estudos de política de ciência e tecnologia pela SPRU

Professor Adjunto de Economia Industrial e da Tecnologia do Instituto de Economia da Universidade Federal do Rio de Janeiro (UFRJ)

Universidade Federal do Rio de Janeiro, Instituto de Economia. Avenida Pasteur 250 Urca CEP 22290- 240 Rio de Janeiro, RJ - Brasil

E-mail: Caetano.penna@pped.ie.ufrj.br

RIO DE JANEIRO 


\section{PRÊMIOS DE RECONHECIMENTO COMO INSTRUMENTO DE PROMOÇÃO À INOVAÇÃO NAS EMPRESAS BRASILEIRAS ${ }^{1}$}

\section{RESUMO}

Este artigo se propõe a analisar a concessão de prêmios de reconhecimento como instrumento de política pública para promover a inovação nas empresas brasileiras. A literatura identifica dois tipos de prêmio de inovação: os de "reconhecimento", que premiam empresas que se destacam por suas inovações já desenvolvidas; e os de "indução", que premiam empresas que desenvolvem a inovação-foco que o prêmio pretende incentivar. Com relação a prêmios de reconhecimento, a literatura nos mostra os benefícios observados para os vencedores, porém nada diz sobre os efeitos gerados aos participantes. Assim, buscou-se investigar como estes podem beneficiar todas as empresas concorrentes, utilizando uma abordagem neo-schumpeteriana e as teorias de aprendizado organizacional para investigar a hipótese de que prêmios de reconhecimento promovem aprendizagem por meio da interação entre os agentes econômicos participantes do prêmio com o patrocinador. Para isso realizou-se uma pesquisa qualitativa em um conjunto de empresas brasileiras que participaram do Prêmio Finep de Inovação entre os anos de 2010 e 2014. Resultados preliminares indicam que a participação das empresas no Prêmio Finep geraram aprendizado e inovações foram introduzidas por elas por conta desta interação. Foi possível também identificar, a partir das entrevistas, a existência de dois tipos de prêmios de reconhecimento, que nomeamos de "estáticos" e "dinâmicos".

Palavras-chave: Prêmio. Inovação. Indução. Reconhecimento. Políticas Públicas. Finep.

\section{ABSTRACT}

This paper proposes to analyze the granting of recognition prizes as an instrument of public policy to promote innovation in Brazilian companies. The literature identifies two types of innovation awards: Recognition prizes, which reward companies that stand out for their innovations already developed; And Inducement Prize, which reward companies that develop the innovation-focus that the prize intends to encourage. Regarding recognition awards, the literature shows us the benefits observed for the winners, but does not say anything about the effects generated for the participants. Thus, we sought to investigate how these can benefit all competing firms by using a neo-Schumpeterian approach and organizational learning theories to investigate the hypothesis that recognition awards promote learning through the interaction between the economic agents participating in the award with the sponsor. For this, a qualitative research was carried out in a group of Brazilian companies that participated in the Finep Innovation Award between the years of 2010 and 2014. Preliminary results indicate that the companies' participation in the Finep Award generated learning for companies, where innovations were introduced by them because of this interaction. It was also possible to identify, from the interviews, the existence of two types of recognition awards, which we call "static" and "dynamic".

Keywords: Inducement. Prize. Recognition. Innovation. Policy. Finep.

Áreas ABEIN : 5.7 Competências e capacitações das empresas e 6.2 Políticas de Ciência, Tecnologia e Inovação

\footnotetext{
${ }^{1}$ Este artigo foi elaborado a partir da dissertação de mestrado do primeiro autor (sob orientação do segundo autor), intitulada "Prêmios de Reconhecimento como Instrumento de Promoção à Inovação nas Empresas Brasileiras", a ser defendida no Instituto de Economia da UFRJ em agosto de 2017. Agradecemos aos pareceristas anônimos os comentários e as sugestões que permitiram aperfeiçoar o texto.
} 
Classificação Journal Economic Literature (JEL): O31 Innovation and Invention: Processes and Incentives e O38 Government Policy

\section{Introdução}

A Margarina, inventada em 1869 na França, constitui um dos produtos alimentícios mais consumidos no mundo. A descoberta do cálculo da coordenada Longitude, ocorrido na Inglaterra em 1756, permitiu uma melhor precisão na localização geográfica dos navios, melhorando a qualidade das navegações e a diminuição de acidentes. A criação da locomotiva The Rocket em 1830, utilizada na primeira estrada de ferro da história, ligando as cidades de Liverpool e Manchester, revitalizou o capitalismo inglês que, a certa altura, mostrava uma tendência de arrefecimento, gerando grandes demandas de ferro, carvão e equipamentos em sua expansão.

O que estas inovações têm em comum? Todas contaram como incentivo receber um prêmio caso a invenção fosse bem-sucedida. A literatura chama este tipo de concessão de "prêmios de inovação".

O principal foco analítico deste artigo são os "prêmios de reconhecimento", um tipo de prêmio de inovação, do qual falaremos mais adiante, como um instrumento capaz de promover a inovação nas empresas e o desenvolvimento econômico. Empiricamente, o artigo analisa o Prêmio Finep de Inovação, utilizando uma abordagem neo-schumpeteriana e as teorias de aprendizado organizacional por meio da interação entre os agentes econômicos participantes do prêmio com a instituição governamental ${ }^{2}$.

Prêmios de reconhecimento são aqueles que consistem em realizar uma retribuição, na forma pecuniária ou não, a um indivíduo ou organização, por alguma realização, em sinal de reconhecimento da excelência. O objeto de realização em questão diz respeito a alguma inovação, normalmente definido de acordos com o "Manual de Oslo" (OCDE, 2005). Esta modalidade se diferencia dos prêmios de indução, que buscam incentivar empresas e/ou indivíduos a criarem uma inovação específica, normalmente para solucionar algum tipo de problema ou conquistar algum desafio tecnológico.

Antigo em sua concepção ${ }^{3}$, utilizados para incentivar a geração de grandes descobertas entre o século XVIII até a primeiro quarto do século XX, prêmios de indução voltaram a atrair a atenção das organizações a partir dos anos 1990 nos Estados Unidos, quando se observa uma inversão no direcionamento de recursos a este tipo prêmios em relação a prêmios de reconhecimento, como mostra a Figura 1.

Neste país, o assunto ganha tal importância que culminou com a autorização por parte do executivo às agencias estatais a utilizar prêmios como instrumento de política objetivando a promoção da inovação (ZIENTS, 2010, p.1).

Figura 1 - Percentual de recursos financeiros direcionados a prêmios nos Estados Unidos

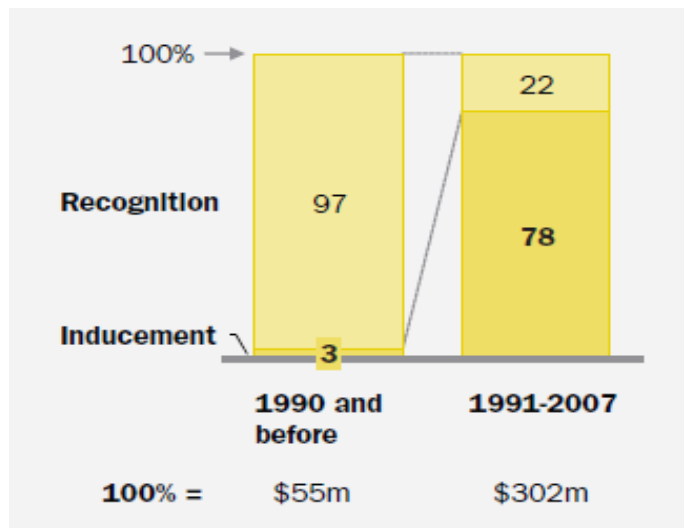

Fonte : (MCKINSEY \& COMPANY,2009,p.17)

\footnotetext{
${ }^{2} \mathrm{O}$ estudo que subsidia este artigo tem como finalidade realizar uma pesquisa empírica que aborde tanto prêmios de reconhecimento como prêmios de indução. O segundo tipo não será abordado neste trabalho.

${ }^{3}$ Os primeiros prêmios de indução foram utilizados a partir do século XVI (BALLANTYNE ,2014, p.9),
} 


\subsection{Os prêmios de inovação à luz da teoria neo-schumpeteriana}

A partir das ideias de SCHUMPETER (1943), que afirma que a inovação constitui o motor do capitalismo e dá às empresas a centralidade ao processo, os neo-schumpeterianos (FREEMAN, 1995; DOSI et. al., 1988; LUNDVALL, 1992) criam o termo Sistemas de Inovação, argumentando que a inovação não é desenvolvida pelas empresas isoladamente, mas sim dentro de um sistema de redes, onde são estabelecidas relações diretas e indiretas, formais ou informais, entre diversas instituições e organizações, tais como instituições de ensino e pesquisa, governo e outras empresas, e levando em consideração o ambiente macroeconômico no qual estão inseridas.

Neste contexto, o desempenho inovativo de um país não depende somente do desempenho de suas empresas e organizações de ensino e pesquisa, mas também de como elas interagem e cooperam entre si e com vários outros atores, os quais não necessariamente estão ligados de forma direta ao processo de desenvolvimento de inovações, como as instituições, o setor financeiro e as políticas macroeconômicas (CASSIOLATO; LASTRES, 2005). Dessa forma, um sistema de inovação é constituído por elementos (instituições e organizações) e relações que interagem na produção, difusão e uso de conhecimentos novos e economicamente úteis (LUNDVALL, 1992).

Assim, dada a importância estabelecida pela literatura que a inovação é um elemento central no desenvolvimento econômico e pela complexidade que envolve o processo inovativo, os formuladores de políticas públicas de inovação definem as estratégias de apoio ao desenvolvimento científico e tecnológico em instituições de pesquisa e nas empresas. Através de suas instituições, o Estado elabora programas, ações e instrumentos de política pública que visam estimular e direcionar as inovações.

No que diz respeito aos instrumentos de apoio concedidos pelo Estado, pode-se considerar, por exemplo, a concessão de patentes, permitindo à empresa garantir o monopólio temporário da exploração da tecnologia utilizada na inovação. Outro tipo de suporte às firmas é na constituição da infraestrutura do ambiente de inovação, seja, por exemplo, na construção de parques tecnológicos ou na formação de incubadoras. O risco financeiro da inovação é compartilhado pelo Estado por meio de diversas formas, sendo os mais utilizados: incentivos fiscais, empréstimos subsidiados e subvenções. Outras formas existentes de apoio pecuniário envolvem a participação societária, a garantia de compra por parte do Estado e a composição de fundos de investimento e participação.

Outro instrumento, antigo em sua concepção, porém historicamente pouco utilizado pelos governos e que tem despertado novamente a atenção, são os prêmios de inovação, utilizados como forma de reconhecer as inovações bem-sucedidas e estimular a geração de produtos, processos e serviços novos e melhorados. Os exemplos citados anteriormente, por exemplo, foram concedidos antes do século XX.

$\mathrm{Na}$ literatura, prêmios se dividem em dois grandes grupos: os chamados prêmios de indução e os de reconhecimento. No primeiro grupo, os patrocinadores definem a tecnologia a ser desenvolvida e suas características e anunciam ao público uma premiação para aquele individuo ou organização que atingir o resultado esperado. Trabalhos recentes mostram que prêmios de indução estimulam a inovação (BRUNT; LERNER; NICHOLAS, 2011). Quanto aos prêmios de reconhecimento, eles objetivam reconhecer os inovadores que atingiram a excelência, sem especificar uma tecnologia a ser estimulada. Os patrocinadores, assim, buscam estimular a inovação através da apresentação de bons exemplos para a sociedade.

A utilização de prêmios de indução como estratégia utilizada por empresas e governos na realização de objetivos tecnológicos, tem atraído cada vez mais a atenção dos formuladores de política pública no exterior, sendo pouco estudado no Brasil, onde predominam os prêmios de reconhecimento. Nestes, a literatura tradicional procura demonstrar os efeitos positivos que o prêmio promove aos vencedores, ignorando os que não foram condecorados.

Por esta razão, este artigo tem como objetivo verificar o potencial que prêmios de reconhecimento possuem em melhorar o desempenho das empresas após sua participação, independentemente de ter vencido um prêmio ou não. Avaliar prêmios de reconhecimento apenas sob a ótica dos vencedores, conforme fazem os autores ROSSINO (2006) e MCKINSEY \& COMPANY (2009, p.48), confere um 
importante viés a estas análises, que perdem de vista o potencial impacto que a participação em tais prêmios exerce (ou não) sobre os demais participantes.

Assim, o artigo propõe-se a investigar, à luz da perspectiva neo-schumpeteriana, a eficácia do uso do maior prêmio de inovação no Brasil, concedido pela Finep, como um instrumento capaz de fomentar a inovação. A hipótese a ser investigada é a de que prêmios de reconhecimento promovem aprendizagem por meio da interação entre os agentes econômicos participantes do prêmio com o patrocinador.

A seguir, em primeiro lugar será brevemente discutido o conceito de aprendizagem num sistema de inovação e, em seguida, será apresentado o Prêmio Finep, principal prêmio de reconhecimento à empresas inovadoras no Brasil.

\subsection{A importância da aprendizagem para a inovação}

Para os neo-schumpeterianos, o conhecimento é considerado um ativo fundamental para se estabelecer vantagens competitivas das empresas, possuindo um papel central no desenvolvimento econômico, não só das firmas, mas da sociedade em geral.

Se o conhecimento é um fator chave, o aprendizado é um elemento fundamental. Se considerarmos o conhecimento o principal ativo das empresas hoje, o aprendizado pode ser considerado o seu principal processo (LUNDVALL, 1992), pois é o que gera novo estoque de informação, tornando possível a inovação. A inovação, portanto, deve ser entendida como o resultado de um processo de aprendizado interativo entre os agentes econômicos e o ambiente o qual interagem (TATSCH, 2009).

MALERBA (1992) identificou, a partir de várias contribuições teóricas, que as firmas aprendem de várias de formas e através de várias fontes de conhecimento, basicamente internas ou externas à firma. Assim, os tipos de processos de aprendizagem das empresas são: (i) aprender-fazendo; (ii) aprenderusando; (iii) aprender a partir de avanços na ciência e tecnologia (iv) aprender buscando e (v) aprender interagindo. A Tabela 1 descreve os tipos de aprendizagem, as fontes de conhecimento e suas respectivas contribuições teóricas.

Tabela 1 - Processos de Aprendizagem

\begin{tabular}{|c|c|c|}
\hline $\begin{array}{l}\text { Tipo de processo de } \\
\text { aprendizagem }\end{array}$ & Fonte de Conhecimento & Contribuição Teórica \\
\hline Aprender-fazendo & $\begin{array}{l}\text { Interna a firma e relacionada à atividade } \\
\text { produtiva }\end{array}$ & $\begin{array}{l}\text { David (1975), Rosenberg } \\
\text { (1976), Silverberg et al. }\end{array}$ \\
\hline Aprender-usando & $\begin{array}{l}\text { Interna a firma e relacionada ao uso dos } \\
\text { produtos, máquinas }\end{array}$ & Rosenberg (1982) \\
\hline $\begin{array}{l}\text { Aprender a partir de avanços na } \\
\text { ciência e tecnologia }\end{array}$ & $\begin{array}{l}\text { Externa à firma e relacionada a absorção de } \\
\text { novos desenvolvimentos na ciência e tecnologia }\end{array}$ & Kline e Rosenberg (1986) \\
\hline Aprender a partir de spillovers & $\begin{array}{l}\text { Externa à firma e relacionada a atividades } \\
\text { desenvolvidas pela concorrência }\end{array}$ & \\
\hline Aprender interagindo & $\begin{array}{l}\text { Externa à firma e relacionada com várias fontes } \\
\text { de conhecimento }\end{array}$ & $\begin{array}{l}\text { Lundvall (1988) e Von } \\
\text { Hippel (1988) }\end{array}$ \\
\hline Aprender buscando & $\begin{array}{l}\text { Interna à firma e relacionada (principalmente) } \\
\text { com atividades de } \mathrm{P} \& \mathrm{D}\end{array}$ & $\begin{array}{l}\text { Sahal (1981), Nelson e } \\
\text { Winter (1982), Dosi } \\
(1988)\end{array}$ \\
\hline
\end{tabular}

Fonte: Elaboração dos autores.

O conceito de aprendizagem por interação fora desenvolvido a partir das ideias de LUNDVALL (1998) e VON HIPPEL (1998), quando estes discutiram aprendizagem através da interação entre produtores e usuários. Para LUNDVALL (1998) quanto mais complexo for o produto a ser desenvolvido, mas é necessária a cooperação do usuário durante o processo inovativo, convergindo para um processo que ambas as partes se beneficiariam. O produtor, por conhecer mais acuradamente as necessidades do usuário. O usuário, entre outros benefícios, obter produtos de acordo com as suas necessidades e treinamento diretamente do produtor, aumentando a relação de confiança entre as partes. 
VON HIPPEL(1998) apresenta uma série de estudos mostrando que as fontes de inovação variam entre usuários, fornecedores e produtores e sugere uma visão de que a inovação é fruto de um processo distribuído entre eles.

O Manual de Oslo dedica um capítulo específico par analisar as interações no processo de inovação. Segundo a publicação, as atividades inovativas dependem como as empresas interagem com as fontes de informação, conhecimentos, tecnologias, recursos humanos e financeiros. As interações atuam como fontes de conhecimento e tecnologia e podem estar relacionados a qualquer um dos tipos de inovação, seja de produto, de processo, de marketing ou organizacional (OCDE, 2005).

Assim, cada interação conecta a empresa inovadora aos atores do sistema de inovação. Os benefícios das interações dependem da capacidade da empresa em administrar o conhecimento adquirido e aplicá-lo no desenvolvimento de inovações.

280 As interações podem gerar conhecimento e tecnologia para qualquer tipo de inovação (seja de produto, de processo, de marketing ou organizacional). Uma grande parte das interações envolve o desenvolvimento de novos produtos ou processos; porém as interações podem também, em muitos casos, envolver a concepção do produto, o desenvolvimento de novas técnicas de marketing, ou o trabalho em inovações organizacionais tais como a integração de empresas com consumidores, fornecedores e varejistas. (OCDE, 2005, p.95).

A partir do exposto, é proposto neste artigo estender as ideias originais destes autores, ao situar o patrocinador de um prêmio de reconhecimento como uma fonte de conhecimento quando este interage com o participante do prêmio, levando, assim, a um uma aprendizagem por interação, para todos os participantes, e não apenas para os vencedores.

\subsection{O Prêmio Finep}

O Prêmio Finep de Inovação foi criado, em 1998, para reconhecer e divulgar esforços inovadores realizados por empresas, instituições sem fins lucrativos e pessoas físicas, desenvolvidos no Brasil e já inseridos no mercado interno ou externo, a fim de tornar o País competitivo e plenamente desenvolvido por meio da inovação. Ao longo das suas edições, contou com mais de 6.000 inscrições e premiou mais de 500 instituições, pessoas físicas e empresas. Ao longo dos anos, a Finep premiou as empresas na forma de subsídios a projetos (na forma de subvenção ou crédito pré-aprovado a juros abaixo do mercado) ou através de recursos pecuniários. Desde 2012, são disponibilizados apenas prêmios em dinheiro, de R $\$ 100$ mil a R $\$ 500$ mil, para os primeiros colocados regionais e nacionais de cada categoria, totalizando uma premiação de R\$ 8 milhões. As categorias são: i) para empresas: Micro/Pequena, Média e Grande Empresa, Tecnologia Assistiva e Inovação Sustentável; ii) para instituições sem fins lucrativos: Instituição de Ciência e Tecnologia, Tecnologia Social; iii) para pessoas físicas: Inventor Inovador e iv) Para firmas gestoras de fundos: Inovar Fundos (FINEP, 2016).

O processo de seleção é composto por duas etapas. Na primeira a Finep efetua a pré-qualificação, de caráter eliminatório, de todas as propostas inscritas, com exceção da categoria Inventor Inovador, que é realizada em parceria com o INPI. Nesta etapa, é verificado o preenchimento correto e completo de todas as informações do formulário de inscrição, bem como o atendimento ao perfil, às condições de participação e às categorias previstas neste regulamento. Na etapa seguinte, as propostas pré-qualificadas são avaliadas por comitês de jurados compostos por especialistas, representantes de instituições inovadoras, do setor empresarial e da Finep. São estabelecidos de 4 (quatro) a 5 (cinco) critérios, onde são dadas notas de 0 (zero) ou 5 (cinco), de acordo com a categoria, e calculada a média aritmética simples. O vencedor é aquele que obtiver a maior média.

Estudos anteriores procuraram identificar os benefícios de se ganhar o Prêmio Finep. ROSSINO (2006) identifica alguns impactos positivos para uma empresa vencedora do prêmio, como estímulo a inovar, geração de propaganda para a empresa, maior facilidade de acesso a financiamentos e a obtenção de maior respeito dos concorrentes.

Um impacto importante notado por ROSSINO (2006) é que ganhar o Prêmio Finep permite a empresa, ao se preparar para competir no prêmio, uma auto-avaliação, dando a elas oportunidades de melhorar seus processos internos e se conhecer melhor, constituindo, assim, uma forma de aprendizado. 
Para a grande empresa, ao participar de um prêmio de reconhecimento, o aprendizado gerado para a empresa vencedora foi considerado mais importante que o prêmio em si.

Este relato isolado de um vencedor que Rossino (2006) cita pode ser melhor investigado, verificando se o aprendizado gerado pela empresa constitui realmente uma externalidade não observada a nível de todos os participantes, constituindo uma das potencialidades não observadas até aqui pelos estudos anteriores, não só do Prêmio Finep, mas de todos os prêmios de reconhecimento. Esta constitui uma das lacunas empíricas que este artigo visa preencher.

No entanto, o Prêmio Finep não promove interação de modo sistemático. Portanto, uma questão em aberto é até que ponto o Prêmio Finep, tal qual está atualmente estruturado, leva a uma aprendizagem generalizada - isto é, se o Prêmio Finep promove aprendizagem tanto do vencedor quanto dos demais participantes - e quais os mecanismos que levam a tal aprendizagem.

Além da introdução, o artigo terá a seguinte estrutura: na seção dois é apresentada a metodologia de pesquisa utilizada, contendo o tipo de pesquisa, a seleção da amostra e a estratégia de análise. A seção três aborda os resultados encontrados e, por fim, na seção quatro, as conclusões.

\section{Metodologia}

A metodologia utilizada neste artigo consistiu, inicialmente, de uma revisão bibliográfica crítica, a partir de material já publicado, como teses, dissertações, livros, artigos de periódicos e materiais disponibilizados na internet nos últimos 15 anos. As palavras chave utilizadas para identificar artigos relevantes foram: políticas públicas, prêmio, inovação, Finep, reconhecimento, indução. Como principais bases de busca, destacaram-se o Portal CAPES ${ }^{4}$, Web of Science (WoS), Scielo, Jstor e Google Scholar. Consultas às bibliotecas também foram efetuadas, para identificar obras de autores clássicos que poderão constituir a fundamentação teórica. A revisão da literatura resultou nas na hipótese anteriormente apresentada:

H1. Prêmios de inovação de reconhecimento promovem aprendizagem por meio da interação entre os agentes econômicos participantes do prêmio com o patrocinador do prêmio.

Para investigar esta hipótese, foi realizado um estudo de caso, utilizando o Prêmio Finep como foco analítico empírico. Como ele concede prêmios para todos os agentes do sistema de inovação, como universidades, centros de pesquisa e inventores pessoa física, este estudo enfocou apenas as empresas inovadoras aprovadas na fase de pré-qualificação ${ }^{5}$, que é a fase em que se avalia se a empresa, a partir do preenchimento do questionário, está aderente a participar do prêmio.

O motivo o qual foi feita a escolha do estudo de caso como a modalidade de pesquisa deste artigo é que, para conseguir testar a hipótese principal, havia a necessidade de se "estudar profundo e exaustivamente poucos objetos, de maneira que permita seu amplo e detalhado conhecimento, tarefa praticamente impossível mediante outros delineamentos já considerados" (GIL, 2002, p.54). Para YIN (2001), ele consiste no delineamento mais adequado quando se deseja estudar um fenômeno dentro do seu contexto real, no caso de um prêmio de reconhecimento, Prêmio Finep, constituindo as empresas participantes os objetos de estudo.

No estudo de caso foi realizada, portanto, uma pesquisa qualitativa, através da técnica de entrevistas, com o auxilio de um "roteiro de perguntas enunciadas pelo entrevistador e preenchidas por ele com as respostas do pesquisado" (MARCONI e LAKATOS, 2009, p.221). A técnica de entrevista utilizada foi a padronizada ou estruturada, definida por como "aquela em que o entrevistador segue um

\footnotetext{
${ }^{4}$ Trata-se de uma biblioteca virtual, mantida pela Fundação CAPES, órgão vinculado do Ministério da Educação do Brasil (MEC), que reúne e disponibiliza a instituições de ensino e pesquisa no Brasil um acervo de mais de 38 mil títulos com texto completo, 134 bases referenciais, 11 bases dedicadas exclusivamente a patentes, além de livros, enciclopédias e obras de referência, normas técnicas, estatísticas e conteúdo audiovisual.

${ }^{5}$ De acordo com Manual de Oslo, "152 Uma empresa inovadora é aquela que implementou uma inovação em um período de análise" (OCDE, p. 56). Consta no regulamento do prêmio Finep, para que a empresa possa ser aprovada na fase de préqualificação, ela deve possuir "ações inovadoras implementadas há pelo menos 3 (três) anos, contados a partir do último dia de inscrição do Prêmio Finep.” (Finep, 2016).
} 
roteiro previamente estabelecido; as perguntas feitas ao indivíduo são predeterminadas." (MARKONI e LAKATUS , op.cit., p.196). O roteiro de perguntas utilizado nas entrevistas conteve somente questões abertas, apresentadas no Apêndice A.

O conjunto de questões foi estruturado em três partes. A primeira teve como objetivo conhecer o perfil do entrevistado; a segunda parte preencher a primeira lacuna levantada neste artigo, obtendo informações à respeito da participação da empresa no Prêmio Finep de Inovação, com o intuito de identificar a existência ou não de aprendizado da empresa, as ações efetuadas, inovações ocorridas como consequência e os efeitos percebidos, procurando, assim, entender em que medida a participação no Prêmio Finep influenciou a estratégia de inovação das empresas ${ }^{6}$. Uma validação inicial do protocolo de perguntas foi feita através de consulta a dois especialistas em políticas de inovação e no sistema de inovação brasileiro.

Para que fosse possível "delinear inferências em relação ao objeto de estudo" (FLICK, 2009, p. 118), foram relacionadas empresas participantes do Prêmio Finep entre 2010 e 2014 que se inscreveram nas categorias: (i) Micro/Pequena Empresa; (ii) Média Empresa e (iii) Grande Empresa. Com o objetivo de a amostra estar homogênea com o universo a ser pesquisado, optou-se por utilizar amostragem do tipo estatística (FLICK, 2009), ainda que tal método seja de menor importância para estudos de caso ${ }^{7}$. De Neste método, os critérios de seleção "são abstratos na medida em que partem de uma ideia de tipicidade e da distribuição do objeto pesquisado" e que "esta noção deve aparecer representada na amostra de material que é estudado" (FLICK, 2009, p.118). As tabelas 2, 3 e 4 descrevem as características da amostra em relação ao total de participantes.

Tabela 2 - $\mathrm{N}^{\mathrm{o}}$ de empresas entrevistadas por Unidade da Federação.

\begin{tabular}{|l|c|c|c|c|}
\hline UF & $\begin{array}{c}\text { No Total de } \\
\text { Participações entre } \\
\text { 2010 e 2014 }\end{array}$ & \% do total & $\begin{array}{c}\text { No de empresas } \\
\text { planejadas a serem } \\
\text { Entrevistadas }\end{array}$ & $\begin{array}{c}\text { Empresas } \\
\text { Entrevistadas }\end{array}$ \\
\hline SP & 260 & $20 \%$ & 5 & 4 \\
SC & 197 & $15 \%$ & 4 & 3 \\
RS & 161 & $12 \%$ & 3 & 2 \\
PR & 117 & $9 \%$ & 3 & 0 \\
RJ & 98 & $7 \%$ & 3 & 6 \\
MG & 71 & $5 \%$ & 0 & 1 \\
AM & 70 & $5 \%$ & 0 & Não se aplica \\
Outros & 337 & $26 \%$ & Não se aplica & 16 \\
\hline Total geral & 1311 & $100 \%$ & 18 &
\end{tabular}

Fonte: Elaboração dos autores.

Algumas características presentes na amostra e população no método estatístico estiveram presentes na metodologia, de acordo com o descrito em FLICK (2009, p.123), que foram: (i) a extensão da população era previamente conhecida; (ii) a distribuição das características da população podia ser estimada e (iii) o tamanho da amostra foi definido previamente.

Assim, foram identificadas 1311 participações no período. Na seleção da amostra, foram observadas as dimensões Unidade da Federação da sede ou filial que concorreu ao prêmio (Tabela 2); o setor em que a empresa atua, utilizando a CNAE de dois dígitos do IBGE (Tabela 3) e o porte da empresa (Tabela 4).

\footnotetext{
${ }^{6}$ A terceira parte, não abordada neste artigo, teve como objetivo verificar se as empresas brasileiras estão dispostas a participar e promover prêmios de indução.

${ }^{7} \mathrm{O}$ tipo de amostragem mais comum em estudos de caso é a 'amostragem intencional' (purposive sampling), através da qual seleciona-se casos de interesse conceitual para o fenômeno estudado (tanto em termos de processo, como de resultado). Para o presente estudo, todo o universo de empresas participantes no Prêmio Finep é de interesse, e, portanto, optou-se por uma amostragem estatística.
} 
Tabela 3 - $\mathrm{N}^{\mathrm{o}}$ de empresas entrevistadas por Setor

\begin{tabular}{|c|c|c|c|c|}
\hline Divisão CNAE & $\begin{array}{c}\text { № Total de } \\
\text { Participações entre } \\
2010 \text { e } 2014\end{array}$ & $\%$ do total & $\begin{array}{c}\text { № de empresas } \\
\text { planejadas a serem } \\
\text { Entrevistadas }\end{array}$ & $\begin{array}{l}\text { Empresas } \\
\text { Entrevistadas }\end{array}$ \\
\hline 62 - ATIVIDADES DOS SERVIÇOS DE TECNOLOGIA DA INFORMAÇÃO & 167 & $17 \%$ & 4 & 5 \\
\hline 26 - FABRICAÇÃO DE EQUIPAMENTOS DE INFORMÁTICA, PRODUTOS ELETRÔNICOS E ÓPTICOS & 69 & $7 \%$ & 2 & 1 \\
\hline 47 - COMÉRCIO VAREJISTA & 65 & $7 \%$ & 2 & 2 \\
\hline 28 - FABRICAÇÃO DE MÁQUINAS E EQUIPAMENTOS & 64 & $7 \%$ & 2 & 2 \\
\hline 20 - FABRICAÇÃO DE PRODUTOS QUÍMICOS & 51 & $5 \%$ & 1 & 2 \\
\hline 71 - SERVIÇOS DE ARQUITETURA E ENGENHARIA; TESTES E ANÁLISES TÉCNICAS & 43 & $4 \%$ & 1 & 0 \\
\hline 10 - FABRICAÇÃO DE PRODUTOS ALIMENTÍCIOS & 36 & $4 \%$ & 1 & 1 \\
\hline 32 - FABRICAÇÃO DE PRODUTOS DIVERSOS & 34 & $3 \%$ & 1 & 1 \\
\hline 46 - COMÉRCIO POR ATACADO, EXCETO VEÍCULOS AUTOMOTORES E MOTOCICLETAS & 33 & $3 \%$ & 1 & 0 \\
\hline 22 - FABRICAÇÃO DE PRODUTOS DE BORRACHA E DE MATERIAL PLÁSTICO & 22 & $2 \%$ & 1 & 1 \\
\hline 27 - FABRICAÇÃO DE MÁQUINAS, APARELHOS E MATERIAIS ELÉTRICOS & 22 & $2 \%$ & 1 & 1 \\
\hline Outros & 705 & $38 \%$ & Não se aplica & Não se aplica \\
\hline Total geral & 1311 & $100 \%$ & 18 & 16 \\
\hline
\end{tabular}

Fonte: Elaboração dos autores.

Tabela 4 - $\mathrm{N}^{\mathrm{o}}$ de empresas entrevistadas por Porte das empresas

\begin{tabular}{|l|c|c|c|c|}
\hline \multicolumn{1}{|c|}{ UF } & $\begin{array}{c}\text { No Total de } \\
\text { Participações entre } \\
\text { 2010 e 2014 }\end{array}$ & \% do total & $\begin{array}{c}\text { No de empresas } \\
\text { planejadas a serem } \\
\text { Entrevistadas }\end{array}$ & $\begin{array}{c}\text { Empresas } \\
\text { Entrevistadas }\end{array}$ \\
\hline Grande & 141 & $11 \%$ & 2 & 3 \\
Média & 122 & $9 \%$ & 2 & 3 \\
Pequena & 1048 & $80 \%$ & 14 & 10 \\
\hline Total geral & 1311 & $100 \%$ & 18 & 16
\end{tabular}

Fonte: Elaboração dos autores.

Objetivou-se entrevistar 18 empresas, sendo contatadas 60, obtendo 16 entrevistas e, assim, uma taxa de resposta de aproximadamente $27 \%$. Escolhidas aleatoriamente, identificou-se posteriormente que nove empresas nunca receberam o Prêmio Finep, três ficaram entre as três primeiras na etapa regional em algum ano, três venceram a etapa regional e uma empresa a etapa Nacional.

Foram entrevistados representantes das empresas com poder decisório, ou que exerceram função relevante e influente na hierarquia decisória, ou até mesmo o funcionário responsável pelo preenchimento do formulário de participação do Prêmio Finep.

Quanto a origem das informações, a relação das empresas pesquisadas foi extraída do banco de dados da Finep, com prévia anuência e autorização da superintendência da área gestora dos dados, tratando-as de forma sigilosa, visando preservar a confidencialidade que a Finep assume com os participantes do concurso.

Procurou-se também priorizar as empresas que tivessem participado mais de uma vez no concurso neste período, ocasionando a participação de 13 das 16 empresas entrevistas com este perfil, de acordo com a Tabela 5.

Tabela 5 - $\mathrm{N}^{\circ}$ de empresas entrevistadas por número de participações durante o período de análise.

\begin{tabular}{|l|c|}
\hline $\begin{array}{c}\text { No de Participações no } \\
\text { Premio Finep entre 2010 e } \\
\mathbf{2 0 1 4}\end{array}$ & $\begin{array}{c}\text { No de Empresas } \\
\text { Entrevistadas }\end{array}$ \\
\hline Uma & 3 \\
Duas & 5 \\
Três & 4 \\
Quatro & 3 \\
\hline Cinco & 1 \\
\hline Total geral & 16 \\
\hline
\end{tabular}

Fonte: Elaboração dos autores. 
De acordo com MARCONI E LAKATOS (2009, p.165), para garantir que os instrumentos de pesquisa sejam válidos e que possuam condições de garantir a realização de seus objetivos, é necessário uma realização de um teste preliminar do questionário (etapa piloto). Para os autores, em geral, de 5\% a $10 \%$ do tamanho da amostra constitui um número razoável para verificar a viabilidade do instrumento e captar erros e sugestões de reformulação. Sendo assim, foi realizado um pré-teste com as duas primeiras empresas entrevistadas, de modo a se validar, junto aos entrevistados, o protocolo de perguntas.

As entrevistas foram realizadas através de contato presencial, telefone ou por email. Com relação ao primeiro tipo, todas foram gravadas, exceto uma, por não ter sido autorizada pelo entrevistador. Os pontos que chamaram a atenção foram anotados durante a realização das entrevistas.

Ao final, realizou-se uma breve análise de conteúdo, seguindo as etapas recomendadas por Bardin (1979): (a) Pré-análise; (b) Exploração do material e (c) Tratamento dos resultados obtidos e interpretação (CAPPELLE et. al., op. cit).

Inicialmente as anotações realizadas em cada entrevista, colocadas em um arquivo texto, e as respostas por email, foram reunidas em uma única planilha eletrônica para uma análise conjunta. Em seguida foi realizada a exploração de cada pergunta realizada. Os resultados foram tratados buscando identificar número de ocorrências de respostas em comum e as diferentes ações tomadas e pontos de vista para, finalmente, realizar uma interpretação e uma conclusão. Há de se mencionar que, por estar ainda em andamento, não foi realizada a transcrição das respostas gravadas, limitando a análise de conteúdo.

\section{Apresentação e discussão dos resultados}

A primeira pergunta da parte II do questionário solicitou as empresas classificar, como um todo, a importância de sua participação no Prêmio Finep e identificar impactos.

Onze das 16 empresas entrevistadas declararam que a participação da empresa no concurso foi importante nos anos em que participou. Alguns relatos mostram que o preenchimento do questionário foi importante para as empresas no sentido de identificar imperfeições nas suas rotinas e mostrá-las a dificuldade em avaliar seus processos de gestão da inovação, ao notar a falta de controle e da presença de indicadores. Uma das empresas declarou que preencher o questionário obriga a ela organizar as ideias, refletir sobre seus processos de inovação e identificar oportunidades de melhoria. Outra empresa informou o impacto que a participação no prêmio impactou positivamente nos processos organizacionais. Uma das empresas entrevistadas afirmou que o prêmio a inspirou a criar programas internos de melhoria em produtos e processos.

Das empresas entrevistadas, 13 das 16 declararam que a participação no Prêmio Finep trouxe reflexões a elas e sete tomaram ações de melhoria, adotando, por exemplo, novas atividades inovativas para a empresa, caso relatado por uma delas, que passou a adotar a prática de patentear seus produtos por entender ser importante para o seu processo de inovação, atribuindo sua mudança de postura à participação no prêmio. Outra empresa relatou que, por conta do prêmio, criou programas de incentivo a inovar dentro de seus colaboradores, gerando, produtos e processos novos e melhorados. Uma das empresas informou que a participação no prêmio ratificou a necessidade de se adquirir um software de gestão, algo que já estava planejado pela empresa. Outra relatou mudanças organizacionais, criando estruturas voltadas à inovação, além de adotar práticas de interação com outros agentes de inovação, se associando a redes de inovação e se dispondo a participar de feiras e exposições. . Algumas firmas relataram que passaram a adotar mais controles com foco em inovação, uma vez que muitas das questões do formulário do prêmio eram quantitativas, aprimorando seus processos de gestão da inovação.

Uma das empresas que relatou que o Prêmio Finep não trouxe reflexões justificou que ela já possuía rotinas e processos de gestão de inovações maduros.

Em seguida, perguntou-se às empresas se elas se consideravam mais ou menos inovadoras após as participações no Prêmio Finep e em que medida o concurso foi relevante para tal.

Oito das 16 empresas consideravam responderam positivamente a esta pergunta. Os motivos foram diversos. Uma das empresas relatou que passou a realizar parcerias. Uma segunda empresa relatou que as reflexões trouxeram oportunidade de aprimorar os seus processos de gestão da inovação. Uma terceira justificou ser mais inovadora por que o prêmio proporcionou a ela formalizar estruturas internas 
voltadas para a inovação. Outra afirmou ter implantado um novo processo de gestão. Uma quinta empresa que participou dois anos seguidos informou que a participação no prêmio no primeiro ano a tornou mais organizada e eficiente, fundamental, segundo ela, para proporcioná-la vencer o Prêmio Finep no seu segundo ano de participação.

Três empresas que acham que suas empresas são mais inovadoras hoje não atribuem ao Prêmio Finep a causa e sete empresas não consideram suas empresas mais inovadoras.

A metodologia utilizada no Prêmio Finep não previa em seus estágios iniciais um retorno da Finep sobre as respostas enviadas, apenas quando na fase em que a empresa concorria na fase nacional, após vencer a etapa regional. Porém, algumas empresas, de acordo com o relato informal de um funcionário que participou na organização do prêmio, receberam retorno das respostas enviadas à instituição quando pediam. Por conta disso, a quarta pergunta do questionário procurou saber se a empresa entrevistada havia recebido algum retorno qualitativo sobre as respostas enviadas. Caso a resposta fosse positiva, procurouse saber a relevância deste para a empresa e, caso contrário, se o possível retorno poderia fazer com a empresa revisasse seus processos internos.

Como de fato era esperado, embora apenas três empresas tenham declarado ter recebido algum tipo de retorno da Finep por parte de algum integrante do seu corpo funcional ou da banca examinadora, nenhum deles foi relevante. Uma das empresas relatou que foi esclarecedor e orientador, sem citar maiores detalhes. As outras duas empresas informaram que o ele ocorreu durante a etapa nacional do prêmio. Um deles disse respeito ao formato da apresentação e outro ocorreu durante a apresentação, em que a banca forneceu a ela alguns pontos de melhoria em seus processos internos.

Para aquelas 13 empresas que não relataram nenhum retorno, quando perguntadas se poderia ser útil a elas, sete delas afirmaram que sim, que poderiam ter revistos seus processos internos. Algumas críticas foram dadas ao prêmio por conta disso, inclusive foi apontado como o motivo de algumas empresas terem desistido a participar de novas edições. Uma delas afirmou que ao menos gostaria de ter recebido um certificado de participação, uma espécie de atestado valorizando a participação da empresa no prêmio.

A quinta pergunta procurou verificar se o preenchimento do formulário trouxe alguma reflexão às empresas sobre seus processos de gestão da inovação e se alguma ação foi tomada por conta desta autoanálise.

Onze das 16 empresas declararam positivamente a pergunta realizada e diversas ações foram relatadas, porém algumas das respostas constituíram em repetição informações prestadas na questão anterior sobre reflexões nos processos internos, mas há de se destacar uma declaração dada por uma empresa, onde passou a adotar processos de gestão onde não existia e outra que passou a adotar programas de melhoria contínua de produtos e processos.

Como o objetivo da pesquisa foi identificar ou não a ocorrência de algum aprendizado da empresa após a participação no Prêmio Finep, isto foi tema da sexta pergunta do questionário. Caso a resposta da empresa posse positiva, pediu-se a ela identificar quais foram as lições aprendidas, as ações tomadas e os efeitos percebidos a partir desta ação.

Onze das 16 empresas entrevistadas declaram a ocorrência de aprendizagem após a participação no Prêmio Finep e, das cinco que responderam negativamente, quando perguntadas se notaram a ocorrência de aprendizado após a participação em outros prêmios de Inovação, três delas responderam positivamente. No caso do Prêmio Finep, algumas das lições aprendidas relatadas foram: (i) contabilizar informações de gestão da inovação; (ii) necessidade de se estruturar e adotar novos processos; (iii) patentes como uma forma de proteção intelectual fundamental para a estratégia da empresa; (iv) exportação como um meio de alcançar melhores resultados; (v) para inovar a empresa tem que comprar a ideia e necessita mobilizar as pessoas, e que trás benefícios para todos os setores da empresas; (vii) sem produção em escala não tem como ser competitivo no mercado; (viii) entender melhor os conceitos de inovação e como contabilizá-los.

Em relação às empresas que relataram aprendizagem através de outros prêmios, evidenciou-se a importância da interação com a patrocinadora. Todas declararam que receberam, e que foi importante para rever seus processos. 
Como última pergunta da parte II do questionário, procurou-se saber se as empresas haviam participado de outros prêmios de inovação. A partir da resposta positiva, identificar resumidamente a ocorrência ou não de aprendizado e identificar ações tomadas.

Embora o enfoque do estudo de caso diga respeito à participação no Prêmio Finep, esta questão tinha como objetivo expandir o teste da primeira hipótese para além do estudo de caso investigado, uma vez que a pergunta de pesquisa diz respeito a prêmios de reconhecimento em geral. Conforme relatado na pergunta anterior, mesmo aquelas que não se lembravam da participação no Prêmio Finep ou não relataram a ocorrência de aprendizagem forneceram relatos de forma que 14 das 16 empresas estudadas informaram a ocorrência de aprendizado em pelo menos um prêmio de reconhecimento que tenham participado.

A partir do resultado das entrevistas, é possível elaborar uma tipologia de prêmios de reconhecimento: haveria dois tipos destes prêmios, que nomeamos de "estáticos" e "dinâmicos", respectivamente. O Prêmio Finep se enquadra na primeira tipologia. A Tabela 6 mostra a diferença entre eles.

Nos prêmios de reconhecimento estáticos não ocorre o retorno sobre as respostas enviadas. Nestes prêmios predominam a aprendizagem por reflexão. Muitas das inovações ocorridas nas empresas entrevistadas relataram melhoria nos processos de contabilização das métricas de gestão da inovação, por conta da necessidade de responder ao formulário. Por outro lado, os prêmios de reconhecimento dinâmicos o patrocinador interage com a empresa durante o processo em que ocorre o prêmio, inspecionando-as. Às vezes ocorre uma verificação das inovações inscritas nos clientes, a fim de identificar sua eficiência e normalmente, ao fim do processo da participação, as empresas recebem um relatório de avaliação, em que identificam falhas e oportunidades de melhoria, dando subsídios para que as empresas aprendam e melhorem nos pontos avaliados.

Tabela 6 - Os tipos de prêmios de reconhecimento quanto a ocorrência de feedback

\begin{tabular}{l|c|c|}
\cline { 2 - 3 } & Estático & Dinâmico \\
\hline Ocorrência de retorno das respostas, feedback & Sem feedback & Com feedback \\
Aprendizagem & Por reflexão, auto avaliação & Por Interação \\
Exemplo de Prêmio & Prêmio Finep & Prêmio Nacional de Inovação (CNI)
\end{tabular}

Fonte: Elaboração dos autores.

\section{Conclusões}

Este artigo se propôs a analisar a concessão de prêmios como instrumento de política pública para promover a inovação nas empresas brasileiras. Investigou-se a hipótese $(\mathrm{H} 1)$ prêmios de inovação de reconhecimento promovem aprendizagem por meio da interação entre os agentes econômicos participantes do prêmio com o patrocinador. Para isso realizou-se uma pesquisa qualitativa em um conjunto de 16 empresas brasileiras que participaram do Prêmio Finep de Inovação entre os anos de 2010 e 2014.

Foram encontrados indícios de que as empresas, mesmo com a ausência de feedback, aprendem através da interação com o patrocinador. O processo de preenchimento do formulário de participação obriga a empresa a se mobilizar para coletar os dados e, nesse momento de integração das pessoas que fornecem as informações, as empresas identificam, pela própria reflexão imposta, lacunas e oportunidades de melhoria nos processos de gestão de inovação, permitindo a elas, em certa medida, realizar ações que variam desde a introdução de atividades inovativas, ajustes em processos ou até mesmo criação de programas e mudanças na estrutura organizacional, ocasionando, assim, na introdução de inovações de processos, de produtos, de marketing e organizacionais.

A partir dos resultados das entrevistas, foi possível propor uma tipologia de prêmios de reconhecimento: estáticos e dinâmicos. Os prêmios estáticos se notabilizam por não haver feedback entre o patrocinador e o participante. 
Como a pesquisa utilizou, como estudo de caso, um prêmio de reconhecimento estático, propõese, como possível avenida de pesquisa futuro, o aprofundamento das questões levantadas em prêmios dinâmicos, como o Premio CNI da Inovação, que diferem do Prêmio Finep, por exemplo, por realizar ações de investigação dos processos de gestão de inovação para empresas que foram aprovadas em fases intermediárias e por entregar relatórios de avaliação.

Há de se salientar que a pesquisa aqui descrita ainda se encontra em desenvolvimento, sendo parte integrante da dissertação de mestrado do primeiro autor, carecendo, portanto, ainda de uma maior precisão da apuração dos resultados. Além disso, a pesquisa se limitou à apenas 16 empresas, em um universo de 973 que participaram do prêmio no período levantado. Uma possibilidade para pesquisa futura é, portanto, fazer análises qualitativas e quantitativas de uma amostra maior de empresas, o que potencialmente aumentará a robustez e a generalização dos resultados encontrados. Por fim, outra avenida para pesquisas futuras é detalhar mais a tipologia aqui proposta, a partir de estudos de prêmios de inovação de reconhecimento de diferentes países (ou internacionais), de modo a colocar os resultados aqui obtidos em perspectiva. 


\section{Referências Bibliográficas}

BALlANTYNE, Perrie. Challenge Prizes - a Practice Guide. Nesta. Disponível em http://www.nesta.org.uk/sites/default/files/challengeprizes-design-practice-guide.pdf. 2014

BRUNT, Liam; LERNER, Josh; NICHOLAS, Tom. Inducement prizes and innovation. The Journal of Industrial Economics, v. 60, n. 4, p. 657-696, 2012.

CAPPELLE, Mônica Carvalho Alves; MELO, Marlene Catarina de Oliveira Lopes; GONÇALVES, Carlos Alberto. Análise de conteúdo e análise de discurso nas ciências sociais. Organizações Rurais \& Agroindustriais, v. 5, n. 1, 2011.

CASSIOLATO, José Eduardo; LASTRES, Helena Maria Martins. Sistemas de inovação e desenvolvimento: as implicações de política. São Paulo em perspectiva, v. 19, n. 1, p. 34-45, 2005.

FINEP. Prêmio FINEP de Inovação, disponível em <http://prêmio.finep.gov.br>. Acesso em 25 de Janeiro de 2016.

FLICK, Uwe. Introdução à pesquisa qualitativa. In: Introdução à pesquisa qualitativa. Artmed, 2009.

FREEMAN, Christopher. The 'National System of Innovation'in historical perspective. Cambridge Journal of economics, v. 19, n. 1, p. 5-24, 1995.

GIL, António Carlos-Como Elaborar Projetos. "de Pesquisa. 4. ${ }^{a}$ Edição." Publicações Atlas (2007).

LUNDVALL, B. A. (ed) National Systems of Innovation: towards a theory of innovation and interactive learning. Anthem Press, 1992.

Innovation as an interactive process: from user-producer interaction to the national system of innovation. In: DOSI, G. et al (orgs.), Technical Change and Economic Theory. Londres: Pinter Publishers, 1988.

MALERBA, F. Learning by firms and incremental technical change. The economic journal, v. 102, n. 413, p. 845-859, 1992.

MARCONI, M. e LAKATOS, M. Metodologia do Trabalho Científico: procedimentos básicos, pesquisa bibliográfica, projeto e relatório, publicações e trabalhos científicos. $7^{\text {a }}$ ed.São Paulo : Atlas, 2009.

MAZZUCATO, M. \& PENNA, C. The Brazilian Innovation System: A Mission-Oriented Policy Proposal. Brasília: CGEE. 2016.

MCKINSEY \& COMPANY. And the winner is: Capturing the power of philanthropic prizes. 2009. Disponível em http://www.mckinsey.com/clientservice/Social_Sector/ our_practices/Philanthropy/Knowledge_highlights/And_the_winner_is.aspx. Último acesso em 26 de agosto de 2016.

OCDE. Manual de Oslo. Diretrizes para coleta e interpretação de dados sobre inovação. 3ª Ed. Brasília, OCDE, Finep, 2005.

ROSINO, A. (2006) “O Prêmio Finep de Inovação Tecnológica”. Niteroi, Rio de Janeiro. 
SCHUMPETER, J. “Capitalismo, Socialismo, Democracia”. Zahar, Rio de Janeiro.

TATSCH, Ana Lúcia. "Conhecimento, Aprendizagem, Inovação e Proximidade Espacial: o caso do arranjo de máquinas e implementos agrícolas no Rio Grande do Sul." Revista Brasileira de Inovação 7.1 jan/jun (2009): 63-100.

VON HIPPEL, E. The sources of Innovation. New York: Oxford University Press. 1988.

YIN, Robert K. Estudo de caso: planejamento e métodos. 2. ed. Porto Alegre: Bookman, 2001.

ZIENTS, J. D. Memorandum for the heads of executive departments and agencies: Guidance on the use of challenges and prizes to promote open government. March, v. 8, p. 2010, 2010. 
Apendice A - Questionário aplicado às empresas que participaram do Prêmio Finep

\section{Parte I - Do Entrevistado}

1. Nome:

2. Cargo ocupado na Empresa:

3. Tempo que ocupa o cargo:

4. Tempo que atua na empresa:

5. Responsável pelo preenchimento do formulário de inscrição no prêmio (Sim/Não):

\section{Parte II - Da Participação no Prêmio Finep}

1. Como você classificaria, como um todo, a participação da sua empresa no Prêmio Finep no(s) ano(s) em que sua empresa participou? Ela foi importante para sua empresa? Como a impactou?

2. O preenchimento do formulário de inscrição no Prêmio Finep trouxe alguma reflexão sobre sua rotina organizacional, no que tange a gestão da inovação?

2.1. Caso afirmativo:

2.1.1. A empresa adotou alguma ação? Se sim, qual? Senão, por quê?

2.2. Caso negativo, por quê?

3. Você considera a sua empresa mais ou menos inovadora após esta(s) participação (ões)?

3.1. Caso afirmativo:

3.1.1. Por quê?

3.1.2. A participação no Prêmio Finep foi relevante para isso?

3.1.2.1. Em caso afirmativo, de que forma?

4. A empresa recebeu algum tipo de retorno sobre as respostas enviadas?

4.1. Caso afirmativo. O retorno foi útil para a empresa? Por quê?

4.2. Caso Negativo. Caso houvesse o retorno, a postura da empresa poderia ter sido diferente, ou seja, a empresa poderia ter revisto seus processos internos?

5. Preencher o formulário trouxe alguma reflexão para a empresa sobre os seus processos de gestão?

5.1. Caso afirmativo:

5.1.1. A empresa adotou alguma ação? Se sim, qual? Senão, por quê?

6. A(s) participação (ões) no Prêmio Finep trouxe(ram) algum aprendizado para a sua empresa?

6.1. Caso afirmativo:

6.1.1. Quais foram as lições aprendidas?

6.1.2. A empresa adotou alguma ação? Qual?

6.1.3. Quais foram os efeitos percebidos? Seria possível estimar em termos quantitativos as mudanças aplicadas?

6.2. Caso Negativo:

6.2.1. Por quê? Você teria alguma sugestão para que o Prêmio Finep pudesse servir de aprendizado para a empresa?

7. A sua empresa já participou de algum outro prêmio de Inovação?

7.1.1. Caso afirmativo,

7.1.1.1. Qual? Como foi esta participação? Descreva.

(identificar aqui se foi prêmio de reconhecimento)

7.1.1.2. $\quad \mathrm{A}(\mathrm{s})$ participação (ões) da sua empresa neste(s) prêmio(s) trouxe(ram) algum aprendizado para a sua empresa?

7.1.1.2.1. Caso afirmativo:

7.1.1.2.1.1. Quais foram as lições aprendidas?

7.1.1.2.1.2. A empresa adotou alguma ação? Qual?

7.1.1.2.1.3. Quais foram os efeitos percebidos? Seria possível estimar em termos quantitativos as mudanças aplicadas? 


\section{Parte III - Prêmios de Indução}

1. Na oportunidade da Finep, ou outra instituição, lançar um prêmio de indução, cujo objetivo tecnológico seja factível de ser alcançado pela sua empresa, ela estaria disposta a participar, mesmo ciente que, não conseguindo ser o vencedor, nenhuma recompensa lhe seja dada?

1.1. Em caso afirmativo, qual seria a sua motivação?

1.2. Em caso negativo, Quais seriam os motivos para que sua empresa não tivesse interesse em participar?

1.2.1. Se o motivo for o cenário politicoleconômico:

1.2.1.1. Havendo condições politicasleconômicas favoráveis, você estaria disposto a mudar de ideia?

1.2.2. Se o motivo for falta de incentivo

1.2.2.1. Se o seu concorrente tomasse a decisão de participar, você estaria disposto a mudar de ideia?

\subsubsection{Outros}

1.2.3.1. Existe algum fator que influenciaria sua mudança na tomada de decisão? Qual seria?

2. Você acredita que sua empresa estaria disposta a lançar um prêmio de indução como uma forma de resolver gargalos tecnológicos e adquirir vantagens competitivas?

2.1. Em caso afirmativo, Por quê?

2.2. Em caso negativo, Quais seriam os motivos para que sua empresa não tivesse interesse em participar?

2.2.1. Se o motivo for o incapacidade técnica:

2.2.1.1. Se a Finep, ou uma outra instituição brasileira, oferecer uma plataforma online para que sua empresa possa divulgar e gerenciar um prêmio de indução e, além disso, disponibilizar uma consultoria para capacitá-la a operar o instrumento, a sua empresa estaria disposta a mudar de ideia? Por quê?

2.2.2. Outros

2.2.2.1. Existe algum fator que influenciaria sua mudança na tomada de decisão? Qual seria? 